\title{
Sector Analysis And Portfolio Optimisation: The Indian Experience
}

Rakesh Gupta, Central Queensland University, Australia Parikshit K. Basu, Charles Sturt University, Australia

\begin{abstract}
With changing global financial environment and emergence of new economic powers in recent decades, diversification of investment portfolios at country and sector levels assumed additional significance. Optimum portfolio selection within a capital market is primarily based on the best risk-return trade-off among the industry sectors. Literature suggests that much of market volatility can be attributed to substantial increase in sector specific and sub-sector specific risks. This research has estimated the dynamics of correlations of stock market returns between industry sectors in India using Asymmetric DCC GARCH model and tested efficient portfolios that generates returns above the market average. Analysis of daily and monthly market data for the period April 1997 to April 2007 on a sample of 10 industry sectors selected randomly indicates that investors can substantially improve their reward to risk as compared with the market returns. Major contributions of this research are two fold. It used a computationally efficient model for estimating correlations that can incorporate the changes in correlations over time and it applied the model for the Indian market where research is extremely inadequate.
\end{abstract}

\section{INTRODUCTION}

C n today's financially integrated world, capital markets in general and stock markets in particular, have become important indicators of performances of economies. As a result, operations of stock market have become a vital area of interest among researchers, investment analysts and policymakers. The stock market is influenced by several factors and from the perspective of an investor it is essential to understand the relationships to optimise returns on investment portfolios.

The primary objective of a financial investor is to achieve an optimal risk-return combination. It can be achieved either by maximizing return with an accepted level of risk or by minimising risk with an acceptable rate of return. Diversification impacts risk component of the portfolio in particular. It enables a spread of investments and allows a middle road through the highs and lows of market performance. It is commonly accepted in investment literature that diversification of portfolio of financial assets generally reduces non-systematic risk. A diversified portfolio does not concentrate in one or two investment categories. Instead, it includes some expected high return investments and some more stable types. The net effect is lower volatility in returns. It allows an opportunity for investments to grow with minimum volatility.

There are different ways and stages to diversify a portfolio. It is done at country, sector (industry), assets and firms (organization) levels. Investment literature conventionally focuses more at asset and firm levels of diversification and paid relatively less attention at country and sector levels. However, with changing global financial environment and emergence of new economic powers in recent decades, diversification at country and sector levels assumed additional significance. Capital markets in emerging economies, like India and China, are growing steadily and these are attracting increasing numbers of global investors. But all sectors within the economies are not growing at a uniform rate. Thus, investment prospects of firms belonging to different sectors could be different. For making investment decisions, it is necessary to consider diversified sectoral performances and prospects in such economies. Optimisation of investment portfolio in such economies can significantly be influenced by sectoral performances.

Literature suggests that much of market volatility can be attributed to substantial increase in sector specific and sub-sector specific risks (Black et al 2002). Performance of the economy influences industry sector returns differently and changes over time periods. Thus, changing pattern of correlations between sectors is vital for portfolio optimisation purposes. However, targeted research in the area of sectoral relationships and their impacts on 
portfolio optimisation is scanty. Research is practically non-existent in the Indian context in particular. The present study attempts to contribute to this specific area of portfolio optimisation using data from the Indian market.

Among the two major emerging economies in the world, capital market in India is more mature and versatile than that of China. This study has estimated the dynamics of correlation of stock market returns between industry sectors in India using Asymmetric DCC GARCH model and tested efficient portfolios that generates returns above the market average. Use of the Asymmetric DCC GARCH model helps in capturing the dynamics of correlations and, as such, a better estimate of the expected future correlations, resulting in a portfolio that reflects future outcomes more closely.

Findings of this research should assist the investors in achieving their primary objective of portfolio optimisation. This, in turn, should increase participation rate and further growth of capital markets in India. The findings can also be generalized for all emerging markets in the world, to a certain extent. It is necessary for emerging economies, like India, to attract capital market investments to sustain their growing needs of economic growth. Findings of this research should help the process of confidence building towards this direction.

\section{LITERATURE REVIEW}

Each sector of the economy typically performs at different levels during different economic cycles, so it is necessary to ensure that the investment portfolio includes a wide range of industry sectors. Review of performances of ten different sectors in the US stock market for the 5-year period (1996-2001) reveals such sectoral differences (Cheng 2001). It showed that the technology sector presented the largest performance swing among all sectors. Sectors like consumer staple, energy, financial and utility were heading down. On the other hand, as the technology bubble burst continued, these sectors began to pick up their performance gradually, with the utility sector posing the most significant gain.

This sector diversification is important for reducing short-term portfolio volatility and ensuring that the portfolio is exposed to emerging investment opportunities in sectors that are growing. Sector distribution, along with asset mix and country allocation, has attracted much attention these days as a means to diversify portfolio risks. Beine et al (2006) analyzed the dynamics of the cross-correlations between the ten Dow Jones European sector financial indices using DCC model and found that the correlations were highly volatile during the IT bubble period (1987-2003). Accordingly, it suggests that the benefits from sector diversification during crises must be taken into account by portfolio managers. However, if the portfolio is properly diversified in other areas, such as asset class and investment style, there is a good chance it is also diversified across a range of industry sectors as well (ibid). The DCC GARCH model has also been used in several other studies (Yang 2005; Jithendranathan 2005; Dunis and Shannon 2005; Gupta 2008). Yang (2005) found that correlations between the returns of selected East and SouthEast Asian markets (Japan, Taiwan, Singapore, Hong Kong and South Korea) changed considerably over the period. Jithendranathan (2005) studied the correlations between the USA and Russian equity markets and found changes in sovereign credit risk, world energy prices and exchange rate to be the reasons for the changes in correlations. Dunis and Shannon (2005) showed that for an unconstrained portfolio of the US and emerging markets (e.g. India, Malaysia and Taiwan), the portfolio weights were significantly different. They found that the Sharpe ratio improved from 1.03 to 1.12 during the period September 2003 to July 2004 by including emerging markets in the optimized portfolio. Asymmetric DCC GARCH model was used by Gupta (2008) for study of international diversification into emerging markets for Australian investors and found that Australian investors could improve their risk adjusted returns by including emerging market stocks in their portfolios.

In the last three decades, a large number of countries had initiated financial reform process to open up their economies and integrated into the global economy. India is one of the late entrants - the reform process officially started in 1991 only. The Indian stock market is possibly one of the oldest in Asia but remained at a small scale and largely outside the global integration process until the late 1980s (Wong et al 2005). The major stock market in India, located in Mumbai (formerly known as Bombay), has always played the dominant role in the equity market in India. It has been traditionally governed by brokers leading to conflict of interest situations between the interest of common investors and those of brokers/owners of stock exchanges (Datar \& Basu 2004). Reforms in equity market in India commenced slightly earlier than the overall reforms (mid-1980s). The opening of stock exchange trading to Foreign Institutional Investors (FIIs) and permission of raising funds from international market through equity linked instruments have introduced a degree of competition to domestic exchanges and other market participants. Coverage of stock exchanges in India, as primary and secondary markets, is expanding steadily. The total amount of 
capital raised through different capital market instruments in India grew by $31.5 \%$ in 2007 over the earlier year (GOI 2008).

Interestingly, stability in prices for the Bombay Stock Exchange (BSE) in India was considered to be an important feature. During the period 1987 to 1994, average annual price fluctuations of ordinary shares on BSE were $25.1 \%$ as compared with $22 \%$ for the London Stock Exchange and $23.9 \%$ for the New York Stock Exchange (23.9\%) (Poshakwale 1996). Regarding efficiency and level of global integration of the Indian stock market, findings are diversified and often contradictory. An early empirical study based on 11 years data (1963-1973) even found evidence of random walk in BSE stocks that could be compared with behaviour of stock prices in the markets like LSE and NYSE (Sharma \& Kennedy 1977). Wong et al (2004) observed that the Indian stock market is integrated with mature markets and sensitive to their dynamics in the long run. In the short-run, the US and Japan markets influenced the Indian market but not vice versa. In particular, the Indian stock markets appear to have integrated more with the global markets since the late 1990s due to lower barriers on foreign investments and growing presence of Indian firms in the international markets (Banerjee \& Sankar 2006). However, more recent data covering the period 1991-2006 for two major equity markets in India (BSE and NSE) found no evidence of random walk in stock prices (Gupta \& Basu 2007). Thus, evidences are contradictory. In any case, with or without explicit validity of random walk model, benefits of diversification cannot be denied. There is no study on benefits of sector diversification in the stock markets of India.

After experiencing very moderate growth until the 1980s, India largely liberalized its economy in the early 1990s. The reforms undertaken by the Indian government in 1991 have resulted in an increase in the economic growth. The growth rate was likely to be about $8.7 \%$ in $2007-08$, slightly lower as compared to $9.4 \%$ and $9.6 \%$ in the previous two years. Global economic slowdown, rise in fuel prices and some degree of cyclical fluctuation could be the possible reasons for the slow down. In the previous five years (2002-07), the average rate of growth of GDP was about $7.8 \%$. Excluding the dismal growth rate of 3.8\% during 2002-03, the next four years' average was $8.8 \%$ (GOI 2008). However, sectoral growth rates varied significantly during this period. Average annual growth rates in transport \& communications (15.3\%) and transport (12.9\%) sectors were much higher than others during the period 2002-2007. Manufacturing, financing and hospitality sectors also did well during this period (GOI 2008).

Studies found strong evidence of relationships between performances of the Indian Stock Market and macroeconomic variables, such as inflation, domestic output growth and macroeconomic management (Naka et al 1999). Panda (2008) observed a long-run relationship between interest rates and stock prices in India. The long-term interest rates are found to affect stock prices negatively, whereas short-term interest rates affect stock prices positively. Another study suggests that stock markets and foreign exchange markets in India are strongly related and they move in tandem with each other (Mishra et al 2007). Thus, financial analysts can obtain more insights in the management of their international portfolio affected by these two variables. This should be important to domestic, as well as international investors, for hedging and diversifying their portfolios.

\section{RESEARCH METHODOLOGY}

The present study has estimated the dynamics of correlations of stock market returns between industry sectors in India using the Asymmetric DCC GARCH model and testing efficient portfolios that generate returns above the market average. Use of the Asymmetric DCC GARCH model helps in capturing the dynamics of correlations and, as such, a better estimate of the expected future correlations, resulting in a portfolio that reflects future outcome more closely. If the risk adjusted returns of the industry selected portfolio is more than the index returns, we could argue that there is value in industry selection and accurate measurement of the correlations helping generate these excess returns. The Asymmetric Dynamic Conditional Correlation (DCC) model of Cappielo et al (2006) is used in this study to estimate the time varying correlations. This model is an introduction of asymmetric term in original DCC model of Engle (2002) as modified by Sheppard (2002) as a general model.

The conditional correlation between two random variables $r_{1}$ and $r_{2}$ that have mean zero can be written as: 
$\rho_{12, t}=\frac{E_{t-1}\left(r_{1, t} r_{2, t}\right)}{\sqrt{E_{t-1}\left(r_{1, t}{ }^{2}\right) E_{t-1}\left(r_{2, t}{ }^{2}\right)}}$

Let $\mathrm{h}_{\mathrm{i}, \mathrm{t}}=E_{t-1}\left(r_{1, t}{ }^{2}\right)$ andri, $t=\sqrt{h_{i, t} \varepsilon_{i, t}}$ for $\mathrm{i}=1,2$, where $\varepsilon_{\mathrm{i}, \mathrm{t}}$

is a standardised disturbance

that has zero mean and a variance of one.

Substituting the above into equation (1) we get:

$\rho_{12, t}=\frac{E_{t-1}\left(\varepsilon_{1, t} \varepsilon_{2, t}\right)}{\sqrt{E_{t-1}\left(\varepsilon_{1, t}{ }^{2}\right) E_{t-1}\left(\varepsilon_{2, t}{ }^{2}\right)}}=E_{t-1}\left(\varepsilon_{1, t} \varepsilon_{2, t}\right)$

Using $\operatorname{GARCH}(1,1)$ specification, the covariance between the random variables can be written as:

$q_{12, t}=\bar{\rho}_{12}+\alpha\left(\varepsilon_{1, t-1} \varepsilon_{2, t-1}-\bar{\rho}_{12}\right)+\beta\left(q_{12, t-1}-\bar{\rho}_{12}\right)$

The unconditional expectation of the cross product is $\bar{\rho}_{12}$, while for the variances

$\bar{\rho}_{12}=1$

The correlation estimator is:

$\rho_{12, t} \frac{q_{12, t}}{\sqrt{q_{11, t} q_{22, t}}}$

This model is mean reverting if $\alpha+\beta<1$. The matrix version of this model is written as:

$Q_{t}=S(1-\alpha-\beta)+\alpha\left(\varepsilon_{t-1} \varepsilon_{t-1}^{\prime}\right)+\beta Q_{t-1}$

Where $\mathrm{S}$ is the unconditional correlation matrix of the disturbance terms and $Q_{t}=\left|q_{1,2, t}\right|$. The log likelihood for this estimator can be written as:

$L=-\frac{1}{2} \sum_{t=1}^{T}\left(n \log (2 \pi)+2 \log \left|D_{t}\right|+\log \left|R_{t}\right|+\varepsilon_{t}^{\prime} R_{t}^{-1} \varepsilon_{t}\right)$

Where $D_{t}=\operatorname{diag}\left\{\sqrt{h_{i, t}}\right\}$ and $\mathrm{R}_{\mathrm{t}}$ is the time varying correlation matrix.

As this model does not allow for asymmetries and asset specific news impact parameters, the modified model Cappiello et al (2006) for incorporating the asymmetrical effect and asset specific news impact is:

$$
Q_{t}=\left(\bar{Q}-A^{\prime} \bar{Q} A-B^{\prime} \bar{Q} B-G^{\prime} \bar{N} G\right)+A^{\prime} \varepsilon_{t-1} \varepsilon_{t-1}^{\prime} A+B^{\prime} Q_{t-1} B+G^{\prime} n_{t-1} n_{t-1}^{\prime} G
$$

Where $\mathrm{A}, \mathrm{B}$ and $\mathrm{G}$ are diagonal parameter matrixes, $\mathrm{n}_{\mathrm{t}}=\mathrm{I}\left[\varepsilon_{\mathrm{t}}<0\right] \mathrm{o} \varepsilon_{\mathrm{t}}$ (with o indicating Hadamard product), $\bar{N}=E\left[n_{t} n_{t}^{\prime}\right]$. For $\bar{Q}$ and $\bar{N}$, expectations are infeasible and are replaced with sample analogues, $T^{-1} \sum_{t=1}^{T} \varepsilon_{t} \varepsilon_{t}^{\prime} T^{-1} \sum_{t=1}^{T} n_{t} n_{t}^{\prime}$, respectively. $Q_{t}^{*}=\left[q_{i i, t}^{*}\right]=\left[\sqrt{q_{i i, t}}\right]$ is a diagonal matrix with the square root 
of the $i^{\text {th }}$ diagonal element of $Q_{t}$ on its $i^{\text {th }}$ diagonal position. In this paper we only look for the asymmetrical effects and not the asset specific news impacts.

\section{Efficient Portfolios}

The efficient frontier is defined as the set of portfolios that exhibit the minimum amount of risk for a given level of return, or the highest return for a given level of risk, and lies above the global minimum variance portfolio. Elton et al (1976) demonstrated a long time ago that it is possible to use a simple decision criterion to reach a optimal solution to the portfolio problem by assuming that a risk-free asset exists, and either the single index model adequately describes the variance-covariance structure, or that a good estimate of pair wise correlations is a single figure. This simple criterion allows one to determine which stocks to include and also how much to invest in each stock. follows:

The former option utilizes the single-index model to construct optimal portfolios. Returns are determined as

$R_{i}=\alpha_{i}+\beta_{i} R_{m}+\varepsilon_{i}$

where $\mathrm{R}_{\mathrm{i}}$ is the return on security $\mathrm{i}$

$\mathrm{R}_{\mathrm{m}}$ is the return on the market index

$\alpha_{i}$ is the return on security $i$ that is indep endent of the market's performance

$\beta_{i}$ is a constant that measures the expected change in $\mathrm{R}_{\mathrm{i}}$ given a change in $\mathrm{R}_{\mathrm{m}}$

$\varepsilon_{i}$ is the random error term with mean of zero and variance of $\sigma_{\varepsilon_{\mathrm{i}}}^{2}$

Assuming that short selling is possible, the task would be to find the unconstrained vector of relative weights for each security so that the Sharpe ratio is maximized. That is:

To find the relative weights, $\mathrm{X}_{\mathrm{i}}{ }^{\prime}$ 's on each security to maximise

the Sharpe ratio, $\theta=\frac{\overline{\mathrm{R}}_{\mathrm{p}}-\mathrm{R}_{\mathrm{f}}}{\sigma_{p}}$

where $\overline{\mathrm{R}}_{\mathrm{p}}$ is the mean return on the portfolio

$\sigma_{p}$ is the standard deviation of the return on the portfolio

Given that

$\overline{\mathbf{R}}_{\mathrm{p}}-\mathbf{R}_{\mathrm{f}}=\sum_{i=1}^{N} \mathrm{X}_{\mathrm{i}}\left(\overline{\mathbf{R}}_{\mathrm{p}}-\mathbf{R}_{\mathrm{f}}\right)$

and

$$
\begin{aligned}
& \sigma_{p}^{2}=E\left(\sum_{i=1}^{N} \mathrm{X}_{\mathrm{i}} \mathbf{R}_{\mathrm{i}}-\sum_{i=1}^{N} \mathrm{X}_{\mathrm{i}} \overline{\mathrm{R}}_{\mathrm{i}}\right)^{2} \\
& \sigma_{p}^{2}=\left[\sum_{i=1}^{N} X_{i}^{2} \beta_{i}^{2} \sigma_{m}^{2}+\sum_{i=1}^{N} \sum_{j=1}^{N} X_{i} X_{j} \beta_{i} \beta_{j} \sigma_{m}^{2}+\sum X_{i}^{2} \sigma_{\varepsilon_{i}}^{2}\right]
\end{aligned}
$$

These equations are substituted into the Sharpe ratio equation, and in order to maximize the Sharpe ratio, it is necessary to take the derivative of the Sharpe ratio with respect to each $X_{i}$ and set it equal to zero. The derivation yields the amount of the portfolio that should be invested $X_{i}^{0}$ in any security as: 


$$
\begin{gathered}
X_{i}^{0}=\frac{\frac{\left(\bar{R}_{j}-R_{f}\right)-C_{0} \beta_{i}}{\sigma_{\varepsilon_{j}}^{2}}}{\sum_{i=1}^{N}\left|\frac{\left(\bar{R}_{j}-R_{f}\right)-C_{0} \beta_{i}}{\sigma_{\varepsilon_{j}}^{2}}\right|} \\
\text { where } \mathbf{C}_{0}=\sigma_{m}^{2} \frac{\sum_{i=1}^{N}\left[\frac{\bar{R}_{j}-R_{f}}{\sigma_{\varepsilon_{j}}^{2}} \beta_{j}\right]}{1+\sigma_{m}^{2} \sum_{i=1}^{N} \frac{\beta_{j}^{2}}{\sigma_{\varepsilon_{j}}^{2}}}
\end{gathered}
$$

By applying equation (11) one should be able to determine the respective weightings for each security within the portfolio and the optimal portfolio's risk and return measures. That is, the risk and returns are obtained by substituting the respective weights found for each security into the returns and variance formula given in (9) and (10), respectively.

\section{Data Requirement}

This research used monthly returns of the National Stock Exchange (NSE) and monthly returns of the different sector indices in India for the period April 1997 to April 2007 for analysis. In order to estimate the volatility of respective indexes, it used daily prices to calculate the daily returns and the daily average volatility of each market index returns. DataStream for index values of the respective equity indexes have been used. The following ten sectoral indexes have been used in this research: abrasives, air conditioners, automobiles 2-wheeler, aluminium, construction, durables, refinery, software, synthetic textiles and trading.

Table 1 presented sector returns and summary statistics for these market sectors. Mean daily returns of the market sectors included in this research varied from $0.5 \%$ for durables to $1.6 \%$ for software sector. There are major differences in the minimum and maximum daily returns for the sectors and, as such, major differences in the variances.

Table 1 : Summary Statistics

\begin{tabular}{|l|c|c|c|c|c|c|}
\hline Sector & Observations & Mean & Skewness & Variance & Min & Max \\
\hline Abrasives & 2608 & 0.0011 & 1.841 & 0.0005 & -0.170 & 0.358 \\
\hline Air conditioners & 2608 & 0.0013 & 0.272 & 0.0005 & -0.142 & 0.125 \\
\hline Aluminium & 2608 & 0.0005 & 0.028 & 0.0005 & -0.127 & 0.108 \\
\hline Automobiles & 2608 & 0.0007 & 0.154 & 0.0003 & -0.118 & 0.097 \\
\hline Construction & 2608 & 0.0013 & 0.259 & 0.0006 & -0.171 & 0.199 \\
\hline Durables & 2608 & 0.0005 & 2.922 & 0.0006 & -0.144 & 0.130 \\
\hline Refinery & 2608 & 0.0006 & -0.023 & 0.0005 & -0.152 & 0.110 \\
\hline Software & 2608 & 0.0016 & -0.059 & 0.0007 & -0.198 & 0.160 \\
\hline Synthetic Textiles & 2608 & 0.0006 & 0.230 & 0.0004 & -0.127 & 0.115 \\
\hline Trading & 2608 & 0.0010 & 0.207 & 0.0005 & -0.118 & 0.178 \\
\hline
\end{tabular}

\section{ANALYSIS OF RESULTS}

The unconditional correlations between sectors for the sample period are presented in Table 2. Lowest correlations were observed between abrasives and software (0.167) and highest between air condioners and durables (0.472). 
Table 2: Unconditional Correlations

\begin{tabular}{|l|c|c|c|c|c|c|c|c|c|c|}
\hline & Abrasives & Aircon & Alum & Autos2 & Construc & Durables & Refinery & Softwa & SyntTex & Trading \\
\hline Abrasives & 1.000 & & & & & & & & & \\
\hline Aircon & 0.219 & 1.000 & & & & & & & & \\
\hline Alum & 0.205 & 0.331 & 1.000 & & & & & & & \\
\hline Autos2 & 0.189 & 0.339 & 0.392 & 1.000 & & & & & & \\
\hline Construc & 0.264 & 0.354 & 0.376 & 0.378 & 1.000 & & & & & \\
\hline Durables & 0.232 & 0.472 & 0.399 & 0.414 & 0.426 & 1.000 & & & & \\
\hline Refinery & 0.232 & 0.377 & 0.437 & 0.386 & 0.441 & 0.443 & 1.000 & & & \\
\hline Softwa & 0.167 & 0.357 & 0.299 & 0.329 & 0.360 & 0.446 & 0.323 & 1.000 & & \\
\hline SyntTex & 0.251 & 0.442 & 0.426 & 0.398 & 0.436 & 0.532 & 0.429 & 0.357 & 1.000 & \\
\hline Trading & 0.224 & 0.309 & 0.291 & 0.285 & 0.363 & 0.378 & 0.353 & 0.332 & 0.357 & 1.000 \\
\hline
\end{tabular}

The focus of this paper is to use conditional correlation estimates (compared with unconditional ones) as it is considered to be more accurate. These correlations are estimated using the Asymmetric Dynamic Conditional Correlation Model (ADCC GARCH). Results are presented in Table 3. The lowest correlation of 0.122 was found between abrasives and aluminium and the highest of 0.575 between construction and refinery. A direct comparison of unconditional correlations from Table 2 and conditional correlations in Table 3 is not meaningful as the argument in favour of conditional correlations lies in theoretical strengths of the Asymmetric DCC GARCH model. Conditional correlations are expected to produce better estimates as the model allows for the correlations to change over time.

Table 3: Conditional Correlations (ADCC GARCH)

\begin{tabular}{|c|c|c|c|c|c|c|c|c|c|c|}
\hline & Abrasi & Airco & Alum & Autos2 & Construc & Durables & Refiner & Softwa & SyntTex & Tradin \\
\hline Abrasives & 1 & & & & & & & & & \\
\hline Aircon & 0.221 & 1 & & & & & & & & \\
\hline Alum & 0.122 & 0.285 & 1 & & & & & & & \\
\hline Autos2 & 0.210 & 0.382 & 0.268 & 1 & & & & & & \\
\hline Construc & 0.355 & 0.333 & 0.466 & 0.476 & 1 & & & & & \\
\hline Durables & 0.218 & 0.358 & 0.345 & 0.432 & 0.446 & 1 & & & & \\
\hline Refinery & 0.235 & 0.407 & 0.408 & 0.439 & 0.575 & 0.454 & 1 & & & \\
\hline Softwa & 0.204 & 0.376 & 0.360 & 0.534 & 0.438 & 0.565 & 0.5116 & 1 & & \\
\hline SyntTex & 0.233 & 0.417 & 0.305 & 0.454 & 0.402 & 0.342 & 0.4169 & 0.333 & & \\
\hline Trading & 0.237 & 0.373 & 0.324 & 0.415 & 0.478 & 0.452 & 0.3764 & 0.367 & 0.348 & 1 \\
\hline
\end{tabular}

In the next step, it is necessary to focus on the mean returns and the Sharpe ratios for the NSE index. These have been used to compare the portfolio returns to assess if the portfolio constructed using the model performs better than the broad based index. Table 4 presents the mean returns for NSE index, also referred to as S \& P Nifty index. The returns of the optimal portfolio using sector indexes for the market and conditional correlations estimated using the ADCC GARCH model are being compared. The 'India only' portfolio (returns for the NSE index) has a mean return of $18.91 \%$ with a standard deviation of $24.48 \%$ and Sharpe ratio of 0.52 based on a risk-free rate of $6 \%$ and a $50 \%$ probability of achieving the target mean returns.

Table 4: S \& P Nifty Index (NSE Index)

\begin{tabular}{|l|c|c|}
\hline & Risk free return 6\% & Risk free return 7.182\% \\
\hline Mean annual returns & $18.91 \%$ & $18.91 \%$ \\
\hline Standard deviation & $24.48 \%$ & $24.48 \%$ \\
\hline Sharpe ratio & 0.52 & 0.48 \\
\hline Probability of achieving mean returns & $50.00 \%$ & $50.00 \%$ \\
\hline
\end{tabular}


The main focus of this paper is the use of the computationally efficient model (DCC Model) for estimating the correlations. In general, conditional correlations in the optimisation model have been to construct optimized portfolio and compare the returns of this portfolio with the S \& P Nifty index. Proportions invested into each market sector, annualized returns and standard deviation of the portfolio are presented in Table 5.

The first set of portfolios was constructed with no short sale in any of the indices, and the improvement in expected return with small or no increase in the risk of the portfolio is evident. Sharpe ratios of the optimized portfolio improved substantially. The Sharpe ratio of the benchmark index was 0.52 as compared with the Sharpe ratio of 0.946 for optimized portfolio that has restrictions of no short sale. Analysis was conducted with different restrictions on the portfolios; maximum of $20 \%$ in one index, $50 \%$ in one index, and up to $100 \%$ of short sale. The Share ratio improved in all cases and, where up to $100 \%$ of short selling is allowed, the improvement in the Sharpe ratio was more pronounced. Consistent improvements in the Sharpe ratio in all cases suggest that these optimal portfolios are superior to the benchmark index. For this analysis, an average risk-free rate was used for estimation of the Sharpe ratios (Chincarni and Kim 2006).

Another risk-adjusted performance measure (M2) is also estimated. The M2 measure is equivalent to the return a portfolio would have achieved if it had the same risk as the benchmark risk (Modigliani and Modigliani 1997). For estimation of M2 measure, the Australian index was used as a benchmark index. The risk adjusted performance (RAP) measure can be calculated as:

$R A P(i)=\left(\sigma_{M} / \sigma_{i}\right)\left(r_{i}-r_{f}\right)+r_{f}$ where $\sigma_{\mathrm{M}}$ and $\sigma_{\mathrm{i}}$ are the volatilities of the market and the stock, $\mathrm{r}_{\mathrm{i}}$ and $\mathrm{r}_{\mathrm{f}}$ are the returns of the portfolio and risk-free returns, respectively and RAP(i) is the risk adjusted performance measure of the portfolio, also sometimes referred to as the M2 measure.

Estimated values of M2 measure are included in Table 5. It clearly indicates that the risk adjusted returns for all the optimal portfolios were higher than the benchmark index. Optimal portfolio with up to $100 \%$ short sale and no restriction on the proportion of investment in the index had the highest Sharpe ratio and highest value of M2 measure as well. Other portfolios with different restrictions also performed better than the benchmark index. Unrestricted optimisation may seem attractive, but market participants at times impose restrictions on the maximum limits on the proportion of the portfolio that can be allocated to one asset. Based on this 'market prudence rule', portfolios with different restrictions have been tested, resulting in similar improvements in the Sharpe ratio and M2 measure.

An analysis was conducted to test if the choice of risk-free rate influences the results (Table 6). It has been observed that the weights assigned to different indexes included within the portfolio may change, but the portfolios are similar in terms of their performance when measured on a risk-adjusted basis using the Sharpe ratio and M2 measure.

Comparisons of Sharpe ratios and the M2 measure in Tables 5 and 6 clearly shows that the portfolios constructed using the conditional correlations had better risk-reward relationship as compared to the benchmark index.

We also look at if the results are influenced by the selection of a portfolio on the efficient frontier. We compare the index with a minimum variance portfolio (without including the risk free asset) and calculate the Sharpe ratio and M2 measure for this portfolio (as given in Table 7) and find that the Sharpe ratio improves and the M2 measure also improves. These results are consistent with the optimal portfolio. 
Table 5: Indian Portfolio with Different Restrictions on Investments into Different Indexes Using ADCC Correlations

\begin{tabular}{|c|c|c|c|c|c|c|c|c|c|c|c|c|c|c|c|}
\hline Country & Abr & Aircon & Alu & Auto & Con & Dur & Ref & Soft & Synt & Tra & $\begin{array}{l}\text { Optimal } \\
\text { Portfolio } \\
\text { Return }\end{array}$ & $\begin{array}{l}\text { Standard } \\
\text { Deviation }\end{array}$ & $\begin{array}{l}\text { Sharpe } \\
\text { Ratio* }\end{array}$ & $\begin{array}{l}\text { M2 } \\
\text { Measure }\end{array}$ & Probability \\
\hline $\begin{array}{l}\text { Investment weights } \\
\text { (No short sale) }\end{array}$ & $18.47 \%$ & $21.16 \%$ & $4.54 \%$ & $4.10 \%$ & $12.15 \%$ & $3.44 \%$ & $0.36 \%$ & $21.28 \%$ & $2.53 \%$ & $11.98 \%$ & 32.09 & 26.35 & .946 & 30.32 & 69.19 \\
\hline $\begin{array}{l}\text { Investment weights } \\
\text { (Max 50\% in one } \\
\text { sector) }\end{array}$ & $18.57 \%$ & $16.65 \%$ & $2.65 \%$ & $2.46 \%$ & $11.50 \%$ & $2.07 \%$ & $3.72 \%$ & $21.68 \%$ & $3.27 \%$ & $17.43 \%$ & 31.99 & 26.48 & .937 & 30.11 & 68.88 \\
\hline $\begin{array}{l}\text { Investment weights } \\
\text { (Max 20\% in one } \\
\text { sector) }\end{array}$ & $16.67 \%$ & $20.00 \%$ & $0.47 \%$ & $7.84 \%$ & $20.00 \%$ & $2.39 \%$ & $0.57 \%$ & $20.00 \%$ & $2.27 \%$ & $9.78 \%$ & 32.68 & 26.89 & .948 & 30.39 & 69.57 \\
\hline $\begin{array}{l}\text { Investment weights } \\
\text { up to } 100 \% \text { short } \\
\text { sale no restrictions } \\
\text { in sectors }\end{array}$ & $60.66 \%$ & $92.74 \%$ & $-73.93 \%$ & $-6.36 \%$ & $76.75 \%$ & $-97.33 \%$ & $-76.76 \%$ & $92.27 \%$ & $-16.72 \%$ & $48.68 \%$ & 89.99 & 68.45 & 1.210 & 36.79 & 84.96 \\
\hline $\begin{array}{l}\text { Investment weights } \\
\text { max } 100 \% \text { short } \\
\text { sale \& } 20 \% \text { in one }\end{array}$ & $20.00 \%$ & $20.00 \%$ & $0.21 \%$ & $20.00 \%$ & $20.00 \%$ & $-35.58 \%$ & $-4.63 \%$ & $20.00 \%$ & $20.00 \%$ & $20.00 \%$ & 36.23 & 28.17 & 1.031 & 32.42 & 73.03 \\
\hline $\begin{array}{l}\text { Investment weights } \\
\text { max } 100 \% \text { short } \\
\text { sale \& } 50 \% \text { in one } \\
\text { sector }\end{array}$ & $19.95 \%$ & $50.00 \%$ & $-28.54 \%$ & $8.65 \%$ & $50.00 \%$ & $-31.81 \%$ & $-38.73 \%$ & $50.00 \%$ & $-29.52 \%$ & $50.00 \%$ & 57.82 & 43.23 & 1.171 & 35.34 & 81.58 \\
\hline
\end{tabular}

* Proxy for Risk free rate is average overnight MIBOR rates for April 1997 to April 2007, available from NSE (7.182\%). 
Table 6: Indian Portfolio with Different Restrictions on Investments into Different Indexes Using ADCC Correlations

\begin{tabular}{|c|c|c|c|c|c|c|c|c|c|c|c|c|c|c|c|}
\hline Country & Abr & Aircon & Alu & Auto & Con & Dur & Ref & Soft & Synt & Tra & $\begin{array}{c}\text { Optimal } \\
\text { Portfolio } \\
\text { Return }\end{array}$ & $\begin{array}{l}\text { Standard } \\
\text { Deviation }\end{array}$ & $\begin{array}{l}\text { Sharpe } \\
\text { Ratio** }\end{array}$ & $\begin{array}{c}\text { M2 } \\
\text { Measure }\end{array}$ & Probability \\
\hline $\begin{array}{l}\text { Investment } \\
\text { weights (No } \\
\text { short sale) }\end{array}$ & $28.16 \%$ & $15.03 \%$ & $5.68 \%$ & $3.16 \%$ & $4.25 \%$ & $0.75 \%$ & $1.09 \%$ & $28.38 \%$ & $7.79 \%$ & $5.72 \%$ & $32.28 \%$ & $26.41 \%$ & 0.995 & 30.35 & 69.33 \\
\hline $\begin{array}{l}\text { Investment } \\
\text { weights (Max } \\
50 \% \text { in one } \\
\text { sector) }\end{array}$ & $22.89 \%$ & $18.05 \%$ & $0.71 \%$ & $6.79 \%$ & $16.60 \%$ & $3.21 \%$ & $0.06 \%$ & $23.40 \%$ & $5.55 \%$ & $2.73 \%$ & $32.69 \%$ & $26.85 \%$ & 0.994 & 30.33 & 69.57 \\
\hline $\begin{array}{l}\text { Investment } \\
\text { weights (Max } \\
20 \% \text { in one } \\
\text { sector) }\end{array}$ & $20.00 \%$ & $20.00 \%$ & $5.08 \%$ & $11.21 \%$ & $8.06 \%$ & $0.58 \%$ & $1.00 \%$ & $20.00 \%$ & $0.53 \%$ & $13.54 \%$ & $31.54 \%$ & $25.63 \%$ & 0.997 & 30.39 & 68.87 \\
\hline $\begin{array}{l}\text { Investment } \\
\text { weights up to } \\
100 \% \text { short sale } \\
\text { no restrictions in } \\
\text { sectors }\end{array}$ & $54.96 \%$ & $94.79 \%$ & $-40.83 \%$ & $-25.83 \%$ & $100.00 \%$ & $-96.14 \%$ & $-79.43 \%$ & $100.00 \%$ & $-51.92 \%$ & $44.40 \%$ & $92.92 \%$ & $69.94 \%$ & 1.243 & 36.42 & 85.54 \\
\hline $\begin{array}{l}\text { Investment } \\
\text { weights max } \\
100 \% \text { short sale } \\
\& \text { max } 20 \% \text { in } \\
\text { one sector }\end{array}$ & $20.00 \%$ & $20.00 \%$ & $-2.24 \%$ & $20.00 \%$ & $20.00 \%$ & $-30.58 \%$ & $-7.18 \%$ & $20.00 \%$ & $20.00 \%$ & $20.00 \%$ & $36.13 \%$ & $27.87 \%$ & 1.081 & 32.46 & 73.13 \\
\hline $\begin{array}{l}\text { Investment } \\
\text { weights max } \\
100 \% \text { short sale } \\
\& \max 50 \% \text { in } \\
\text { one sector }\end{array}$ & $50.00 \%$ & $50.00 \%$ & $8.19 \%$ & $3.40 \%$ & $30.53 \%$ & $-66.64 \%$ & $-21.12 \%$ & $50.00 \%$ & $-30.67 \%$ & $26.32 \%$ & $55.82 \%$ & $41.44 \%$ & 1.202 & 35.43 & 81.26 \\
\hline
\end{tabular}

** Proxy for Risk free rate is overnight MIBOR rate for end April 2007, available from NSE (6\%). 
Table 7: Minimum Variance Portfolio weights

\begin{tabular}{|l|l|}
\hline Abrasives & 0.2011 \\
\hline Air-conditioning & 0.0922 \\
\hline Aluminium & 0.1936 \\
\hline Autos & 0.2894 \\
\hline Construction & 0.0 \\
\hline Durables & 0.0 \\
\hline Refinery & 0.0380 \\
\hline Software & 0.0 \\
\hline S. Textiles & 0.1214 \\
\hline Trading & 0.0642 \\
\hline Standard Deviation & 0.2240 \\
\hline Expected Return & 0.2244 \\
\hline Sharpe ratio (6\% risk free rate) & 0.7339 \\
\hline Sharpe ratio (7.182 \% risk free rate) & 0.6811 \\
\hline M2 measure (6\% risk free rate) & 23.96 \\
\hline M2 measure (7.182\% risk free rate) & 23.85 \\
\hline
\end{tabular}

\section{CONCLUSIONS}

The role and importance of sector selection in investment portfolios has been focused in this quantitative research using a sample of ten industry sectors for equity markets in India. As sector or industry selection is becoming more important in the financial world, the correlations between industries can act as important indicators for portfolio optimisation. Again, if correlations between industry sectors are important, then it is necessary to have accurate estimates of correlations. The Asymmetric DCC GARCH model provides theoretically better estimates of correlations. This paper used the DCC GARCH model to estimate conditional correlations between ten industry sectors in India using data from its National Stock Exchange for a fairly long period (1997-2007). Results of this research indicate that a portfolio constructed using conditional correlations performs better than a benchmark index. If an investor has a choice of investing in a benchmark index or constructing its own portfolio using different indices, the investor can earn higher risk-adjusted returns by constructing a portfolio of assets using different industry sectors.

The main contribution of this research is in using a computationally efficient model for estimating correlations that can incorporate the changes in correlations over time. The suggested model is theoretically sound and computationally efficient and can be used with a number of assets. Another contribution of the study is to demonstrate that the correlations between asset returns change over time. So far, this aspect of asset correlations has largely been ignored in the literature. The demonstration of changes in correlations suggests that there is need for understanding the dynamics of changes in correlations over time. The accurate estimation of these correlations can help an investor in choosing a portfolio that is superior in its risk and return combination to the benchmark index.

\section{AUTHOR INFORMATION}

Rakesh Gupta is a lecturer at CQ University, Rockhampton, QLD, Australia. He has taught as a visiting faculty member at different universities around the world. Rakesh teaches in the area of finance, investments and personal financial planning. His main research interests include international investments, international diversification, including diversification into emerging markets and behaviour of emerging market derivatives. He has extensively published in international journals of repute.

Dr. Parikshit K Basu is a senior lecturer and Associate Head of the School of Marketing and Management, Charles Sturt University, Australia. Dr. Basu is an applied researcher in the financial economics area. He is presently involved in research on financial globalization, capital markets in emerging economies, China-Australia business relationships, regional labour markets, ethnic issues and teaching methods. He has extensive publications in international journals, book chapters and conference volumes. He has edited two books and the third one will be forthcoming in about six months. 


\section{REFERENCES}

1. Banerjee, S. and Sankar, S. 2006, 'Measuring Market Integration in Indian Stock Market', Finance India, 20(3), pp. 895-912.

2. Beine, M.; Preumont; Pierre-Yves; and Szafarz, A., 2006, "Sector diversification during crises: A European perspective," Working Papers DULBEA 06-07.RS, Université libre de Bruxelles, Department of Applied Economics (DULBEA).

3. Black, A. J. Buckland, R. and Fraser, P. 2002, 'Efficient Portfolio Diversification: Changing UK Stock Market Sector and Sub-Sector Volatilities, 1968-2000', Managerial Finance, 28(9), pp26 - 43.

4. Cappiello, L. Engle, R. and Sheppard, K. 2006, Asymmetric Dynamics in the Correlations of Global Equity and Bond Returns, Journal of Financial econometrics, Advance Access published online on September 25, 2006

5. Cheng, C. 2001, 'Sector Diversification', Morningstar, http://www.hk.morningstar.com/HKG/ARTICLES/FEATUREARTICLE.ASP?ArticleId=\%2FODS\%2F20 00\%2FFATT\%2F2000FATT164E_20010713.XML\&change needed=EN, viewed in May 2008

6. Chincarini, L.B. \& Kim, D., 2006. Quantitative Equity Portfolio Management: An Active Approach to Portfolio Construction and Management, McGraw-Hill, New York.

7. Datar, M. K. and Basu, P. K. 2004 'Financial sector reforms in India: Some institutional imbalances', Conference Volume, Academy of World Business, Marketing and Management Development Conference, Gold Coast, Australia, July.

8. Dunis, C.L. \& Shannon, G., 2005. Emerging markets of South-East Asia and Central Asia: Do They Still Offer a Diversification Benefit? Journal of Asset Management, vol. 6, no. 3, pp.168-190.

9. Elton, E. J., Gruber, M. J. and Padberg, M. W. 1976, Simple criteria for optimal portfolio selection, Journal of Finance, vol. 31, no. 5, pp 1341-1357.

10. Engle, R. 2002, Dynamic Conditional Correlation - A Simple Class of Multivariate GARCH models, Journal of Business and Economic Statistics, 20, 339-350.

11. Government of India 2008, Economic Survey 2007-08, New Delhi: Ministry of Finance, http://indiabudget.nic.in/es2007-08/esmain.htm (viewed in May 2008).

12. Gupta, R., 2008, 'Time-varying Correlations and Optimal Allocation in Emerging Market Equities for Australian Investors', paper presented at 2008 AFFANZ conference, $6^{\text {th }}$ to $8^{\text {th }}$ July 2008 Sydney

13. Gupta, Rakesh and Basu, P K 2007, 'Weak form efficiency in Indian Stock Markets', International Business \& Economics Research Journal, Vol. 6, (3), pp. 57-64.

14. Jithendranathan, T., 2005. What Causes Correlations of Equity Returns to Change Over Time? A Study of the US and the Russian Equity Markets. Investment Management and Financial Innovations, vol. 4, pp. 6979.

15. Mishra, A. K.; Swain, N.; and Malhotra, D. K. 2007, 'Volatility Spillover between Stock and Foreign Exchange Markets: Indian Evidence', International Journal of Business, Vol 12, No. 3, pp. 233-51.

16. Modigliani, F. \& Modigliani, L., 1997. Risk-Adjusted Performance. Journal of Portfolio Management, Winter, vol. 23, no. 2, pp. 45-54.

17. Naka, A.; Mukherjee, T. K. and Tufte, D. R. (1999) 'Macroeconomic Variables and the Undervalued Indian Stock Markets’, Financial Management Association meeting, Orlando, October, http://business.uno.edu/econ/staff/naka.html (viewed in October 2007.

18. http://www.nse-india.com/content/debt/debt statistics.htm viewed on 15th May 2007.

19. Panda, C. 2008, 'Do Interest Rates Matter for Stock Markets?', Economic and Political Weekly, Vol 43, No. 21, pp. 107-15

20. Poshakwale, S. 1996, Evidence on Weak Form Efficiency and Day of the Week Effect in the Indian Stock Market. Finance India, Vol X, No. 3. 605-616

21. Sharma, J. L. and Kennedy, R. E. 1977, 'A comparative analysis of stock price behaviour on the Bombay, London, and New York stock exchanges', Journal of Financial and Quantitative Analysis, September.

22. Sheppard, K., 2002. Understanding the Dynamics of Equity Covariance. Manuscript, University of California, San Diego.

23. Yang, S.Y., 2005. A DCC Analysis of International Stock Market Correlations: The Role of Japan on the Four Asian Tigers. Applied Financial Economic Letters, vol. 1, no. 2, pp. 89-93.

24. Wong, Wing-Keung; Agarwal, A. and Du, Jun 2005, 'Financial Integration for India Stock Market, a Fractional Cointegration Approach', Departmental Working Papers wp0501, National University of Singapore, Department of Economics, http://nt2.fas.nus.edu.sg/ecs/pub/wp/wp0501.pdf (viewed in October 2007. 